BMJ Open

Diabetes

Research

\& Care

\title{
Simple and non-invasive screening method for diabetes based on myoinositol levels in urine samples collected at home
}

\author{
Misaki Takakado, ${ }^{1}$ Yasunori Takata (D) , ${ }^{1}$ Fumio Yamagata, ${ }^{2}$ Michiko Yaguchi, ${ }^{2}$ \\ Go Hiasa, ${ }^{3}$ Sumiko Sato, ${ }^{4}$ Jun-ichi Funada, ${ }^{5}$ Shoji Kawazu, ${ }^{2,6}$ Haruhiko Osawa ${ }^{1}$
}

To cite: Takakado M, Takata Y, Yamagata F, et al. Simple and non-invasive screening method for diabetes based on myoinositol levels in urine samples collected at home. BMJ Open Diab Res Care 2020;8:e000984. doi:10.1136/ bmjdrc-2019-000984

- Additional material is published online only. To view please visit the journal online (http://dx.doi.org/10.1136/ bmjdrc-2019-000984).

Received 15 October 2019 Revised 1 January 2020 Accepted 7 January 2020
Check for updates

(c) Author(s) (or their employer(s)) 2020. Re-use permitted under CC BY-NC. No commercial re-use. See rights and permissions. Published by BMJ.

For numbered affiliations see end of article.

Correspondence to Dr Yasunori Takata; ytakata@m.ehime-u.ac.jp

\section{ABSTRACT}

Objective To establish a simple screening method for diabetes based on myoinositol (MI) in urine samples collected at home.

Research design and methods Initially, we evaluated the stability of urinary MI (UMI) at room temperature (RT; $25^{\circ} \mathrm{C}$ ) and $37^{\circ} \mathrm{C}$ in 10 outpatients with type 2 diabetes. We then enrolled 115 volunteers without a current or history of diabetes. In all subjects, glucose intolerance was diagnosed by $75 \mathrm{~g}$ oral glucose tolerance test (75g0GTT). To assess the association between UMI or urine glucose (UG) and plasma glucose (PG), urine samples were also collected at 0 and 2 hours during $75 \mathrm{gOGTT}$. All the subjects collected urine samples at home before and 2 hours after consuming the commercially available test meal. UMI levels at wakeup time (UMI $\left.\left.\right|_{\text {wake-up }}\right)$, before (UMI the test meal (UMI $\left.\left.\right|_{2 \text { h-postronandial }}\right)$ were measured using an enzymatic method. $\triangle U \mathrm{UMI}$ was defined as $\mathrm{UMI}_{2}$ minus UMI premeal .

Results Differing from UG, UMI was stable at RT and $37^{\circ} \mathrm{C}$. UMI was increased linearly along with an increase in PG, and no threshold for UMI was observed. UMI was closely associated with blood glucose parameters obtained from a 75gOGTT and hemoglobin A1c (HbA1c) at hospital after adjustment for age, sex, body mass index and serum creatinine. $U \mathrm{UMI}_{\text {wake-up }}, \mathrm{UMI}_{\text {premeal }}, \mathrm{UMI}_{\text {2h-postorancial }}$ and $\Delta \mathrm{UMI}$ at home were higher in diabetic subjects than non-diabetic subjects even after the above adjustment. Receiver operating characteristics curve (ROC) analyses revealed that for the screening of diabetes, the area under the

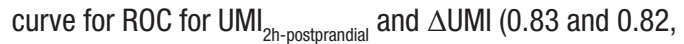
respectively) were not inferior to that for $\mathrm{HbA} 1 \mathrm{C} \geq 48 \mathrm{mmol} /$ mol, which is the American Diabetes Association (ADA) criteria for diabetes.

Conclusions $\mathrm{Ml}$ measurement in urine samples collected at home before and after the meal would be a simple, noninvasive and valuable screening method for diabetes.

\section{INTRODUCTION}

According to the International Diabetes Federation, the population of subjects with diabetes is explosively increasing in the world. ${ }^{1}$ The number of patients with diabetes is estimated to be about 400 million, ${ }^{2}$ and

\section{Significance of this study}

What is already known about this subject?

- Urinary myoinositol (UMI) is increased in subjects with diabetes. Therefore, measuring UMI during a $75 \mathrm{~g}$ oral glucose loading is a useful and noninvasive screening method for diabetes at hospital. However, it has not been widely accepted because it cannot be used as a diagnosis of diabetes, even if it is performed at hospital. We therefore conducted studies to establish a simple screening method for diabetes based on myoinositol levels in urine samples collected at home.

What are the new findings?

D Different from urinary glucose (UG), UMI was stable at room temperature (RT) and $37^{\circ} \mathrm{C}$. The estimated shelf life of UMI was sufficiently long to permit a urine sample collected at home to be mailed to the laboratory without preservative. Different from UG, no threshold for UMI was observed, and UMI was increased linearly along with an increase in plasma glucose. Therefore, the properties of UMI permit it to screen early stage of diabetes.

- UMI levels from urine samples self-collected at home were closely associated with blood glucose parameters obtained from a $75 \mathrm{~g}$ oral glucose tolerance test (75gOGTT) and HbA1c at hospital. UMI was higher in subjects with diabetes than non-diabetes at wakeup time, premeal, 2 hours after ingestion of test meal and $\triangle \mathrm{UMI}_{0-2 \mathrm{~h}}$ at home. For the screening of diabetes, the area under the curve for receiver operating characteristics for UMl at 2 hours after ingestion of test meal and $\triangle U \mathrm{UI}_{0-2 \mathrm{n}}$ at home were not inferior to that for $\mathrm{HbA} 1 \mathrm{C} \geq 48 \mathrm{mmol} / \mathrm{mol}(6.5 \%)$, which is the ADA criteria for diabetes at hospital $(0.83,0.82$, and 0.90 , respectively).

a quarter of them are not aware that they have diabetes. ${ }^{3}$ Moreover, the lifestyle or pharmaceutical interventions for subjects with impaired glucose tolerance (IGT) but not impaired fasting glucose (IFG) could prevent the progression of diabetes and 


\section{Significance of this study}

How might these results change the focus of research or clinical practice?

> Screening for diabetes by mailing self-collected urine samples from home to the laboratory to measure UMI would enable us to select appropriate subjects who would need to have advanced examinations such as a $75 \mathrm{gOGTT}$. The UMI test would be suitable for subjects with limited access to medical care because of financial problems and locality and would be the first step towards further medical examinations. It would lead to a more cost-effective screening for diabetes.

cardiovascular disease. ${ }^{4-7}$ Therefore, to prevent them, the early detection of glucose intolerance (GI), especially postprandial hyperglycemia, is highly desirable. ${ }^{89}$ However, in the incipient stage of diabetes, there are few subjective symptoms. ${ }^{10}{ }^{11}$ Because of this, the majority of such patients rarely visit a hospital, leading to a delay in the initiation of treatment. ${ }^{12}{ }^{13}$ Furthermore, $70 \%$ of subjects with diabetes live in developing countries, and access to medical care is frequently limited because of limited finances and a shortage of physicians. ${ }^{3}$ Therefore, there is an urgent need to develop a simple, non-invasive, inexpensive, and precise mass-screening method that is available at home and would enable them to take the first steps toward undergoing further advanced examinations such as measuring fasting plasma glucose (FPG), hemoglobin A1c (HbA1c) and a $75 \mathrm{~g}$ oral glucose tolerance test (75gOGTT) at hospital.

Myoinositol (MI; molecular weight 180.16) is structurally similar to D-glucose, and it is widely distributed in multiple organs. ${ }^{14} 15$ The reabsorption of MI in renal tubules competes with urinary glucose (UG) in cases of hyperglycemia, resulting in high concentrations of MI being excreted into the urine. ${ }^{16}$ It has been reported that urinary myoinositol (UMI) levels are increased in subjects with diabetes compared with controls. ${ }^{16}{ }^{17}$ In healthy subjects, approximately $16 \sim 30 \mathrm{mg} /$ day of MI is excreted in the urine, whereas, in subjects with diabetes, this level is increased to about $150 \sim 220 \mathrm{mg} /$ day. ${ }^{1718}$ It has been reported that $\Delta \mathrm{UMI}$, which is defined by a 2-hour post-75 g oral glucose loading UMI minus preload UMI, is a useful and non-invasive method for screening for GI. ${ }^{19}{ }^{20}$ However, different from a regular $75 \mathrm{gOGTT}$, measuring UMI during a $75 \mathrm{~g}$ oral glucose loading cannot be used as a diagnosis of GI, even if it is performed at hospital. Therefore, measuring UMI to screen for GI in hospital has not been widely accepted. We therefore conducted studies to establish a simple screening method for undiagnosed diabetes based on MI levels in urine samples collected at home.

\section{MATERIALS AND METHODS}

\section{Measurement of UMI}

UMI was measured using an enzyme cycling method with MI dehydrogenase (Lucica MI, Asahi KASEI Pharma Co). ${ }^{20}{ }^{21}$ The sensitivity of detection was $10 \mu \mathrm{mol} / \mathrm{L}$, and the coefficient of variation (CV) was $0.5 \% \sim 1.1 \%$. Interassay and intra-assay $\mathrm{CV}$ were $0.5 \% \sim 1.1 \%$ and $0.4 \% \sim 1.3 \%$, respectively. ${ }^{21}$ To reduce the influence of renal function, UMI was corrected by urinary creatinine (UCr), except for stability test.

\section{Study design and population \\ Study 1: testing the stability of UMI, UG and UCr at room temperature (RT) and $37^{\circ} \mathrm{C}$}

Regarding mailing urine samples collected at home to a laboratory, we first evaluated the stability of UMI, UG, and $\mathrm{UCr}$ at RT $\left(25^{\circ} \mathrm{C}\right)$ and under relatively severe conditions such as $37^{\circ} \mathrm{C}$. Urine samples from 10 arbitrary outpatients with type 2 diabetes mellitus (T2DM) at Ehime University Hospital were stored without preservative in an incubator at $25^{\circ} \mathrm{C}$ or $37^{\circ} \mathrm{C}$ for $0,1,2,3,5$, and 7 days. UMI, UG and $\mathrm{UCr}$ concentrations were measured at each of the above time points to assess the stability.

Study 2: the clinical usefulness of MI in urine samples collected at home before and after the ingestion of the test meal

We consecutively recruited Japanese volunteers who were attending medical check-up at Kitaishikai Hospital, Saijyo Central Hospital and Ehime University Hospital. Subjects with a current or history of diabetes and chronic renal dysfunction based on an estimated glomerular filtration rate (eGFR) of $<30 \mathrm{ml} / \mathrm{min} / 1.73 \mathrm{~m}^{2}$ were excluded. To diagnose GI (IGT or diabetes), we performed a $75 \mathrm{gOGTT}$ at hospital, and their HbAlc levels were measured. A diagnosis of IGT and diabetes were defined according to either FPG or 2-hour plasma glucose level after a 75 gOGTT or the HbAlc based on American Diabetes Association (ADA) criteria. ${ }^{22}$

To assess the association between UMI or UG and plasma glucose (PG), we also collected urine samples at 0 and 2 hours after glucose ingestion from a sequence of 46 subjects at Ehime University Hospital. These urine samples, without preservative, were immediately shipped to a single laboratory (Bio Medical Laboratories, Inc) at ambient temperature $\left(5^{\circ} \mathrm{C}-26^{\circ} \mathrm{C}\right.$ in Ehime prefecture), and UMI and UG levels were measured within 24 hours of the urine collection.

Within a week after the $75 \mathrm{gOGTT}$ at hospital, the participants ingested a test meal (commercially available energy bar: Calorie Mate $500 \mathrm{kcal}$ : carbohydrate $51 \mathrm{~g}$, fat $28 \mathrm{~g}$, protein $11 \mathrm{~g}$, Otsuka Pharmaceutical Co, Ltd) at home. ${ }^{23} 24$ There was a close correlation between plasma glucose levels at 2-hour post-75gOGTT and at 1 hour postingestion of this test meal $\left(R^{2}=0.67, \mathrm{p}<0.001\right)$.

The participants collected urine samples $(15 \mathrm{~mL})$ at home at three points: (1) wake-up time (fasting first urine), (2) premeal (0 hour, 08:00), and (3) 2 hours after ingestion of the test meal (2-hour postprandial, 10:00). These urine samples without preservative were shipped to a single laboratory at ambient temperature, and the UMI and UCr levels were then measured within 2 days of their collection (online supplementary figure 1). The 
$\Delta \mathrm{UMI}$ was defined as the 2-hour postprandial UMI minus the premeal UMI.

Written informed consent was obtained from all participants prior to their enrollment in this study.

\section{Statistical analysis}

To assess the stability of UMI, UG, and UCr, we calculated the CV from 0 to 7 days. We considered samples to be stable if CV was within $5 \%$. We also estimated the shelf life as previously described ${ }^{25-27}$ Briefly, the shelf life data were calculated from the regression line $(95 \%$ confidence limits line) of 6 data points $(0,1,2,3,5$, and 7 days) and the lower acceptance criteria of $90 \%$ of the reference (day 0 ).

To evaluate the association between glucose parameters and UMI, we performed multivariate regression analyses adjusted for age, sex, body mass index (BMI), and serum creatinine. The Mann-Whitney test was used to compare the subjects with or without diabetes. Differences in longitudinal data in the two groups were assessed by repeatedmeasure analysis of variance (ANOVA). To compare the normal glucose tolerance (NGT), IGT, and T2DM, one-way ANOVA or Kruskal-Wallis test were used. The values were expressed as the mean $\pm \mathrm{SD}$ or $\mathrm{SE}$. To determine the utility of UMI for screening of diabetes or GI, we performed receiver operating characteristics (ROC) curve analyses based on STARD 2015 guidelines..$^{28}$ Based on a previous report, ${ }^{19}$ we calculated the required sample size. The data indicated that a sample size of 44 would be needed to detect a minimum difference between the groups for a $5 \%$ change $(\alpha=0.05,90 \%$ power $)$. Statistical analyses were carried out using JMP V.13. Difference yielding $\mathrm{p}<0.05$ was considered to be statistically significant.

\section{RESULTS}

Study 1

UMI was stable at RT and $37^{\circ} \mathrm{C}$

We first evaluated the stability of UMI and UG from 10 outpatients with T2DM. Their clinical characteristics are summarized in online supplementary table 1 . Stability tests revealed that, at RT, the CV of UMI from 0 to 7 days were less than $5 \%$. Even under severe conditions such as $37^{\circ} \mathrm{C}$, UMI was stable and CVs were less than $5 \%$ except for one sample. In contrast, UG was unstable at RT. In most of the samples, the CV of UG from 0 to 7 days were more than $5 \%$ at RT. This phenomenon was even more obvious at $37^{\circ} \mathrm{C}$ (online supplementary table 1 ). The estimated shelf life of UMI was sufficiently long to permit a urine sample collected at home to be mailed to the laboratory when stored at $\mathrm{RT}$ and $37^{\circ} \mathrm{C}$ (46 days and 18 days, respectively). However, the estimated shelf life of $\mathrm{UG}$ was very short at $\mathrm{RT}$ and $37^{\circ} \mathrm{C}$ ( 1 day and 0 day, respectively). Furthermore, the estimated shelf life of UCr was 7 days at RT and 2 days at $37^{\circ} \mathrm{C}$.

Therefore, we focused on the usefulness of UMI for screening for undiagnosed diabetes in urine samples collected at home.

\section{Study 2 \\ Characteristics of the participants in the study 2}

We enrolled 115 Japanese volunteers without a current or past history of diabetes. Their clinical characteristics are summarized in table 1 . A 75gOGTT revealed that 63 subjects had NGT, 29 had IGT, and 23 had T2DM. FPG and HbA1c in the T2DM group were $6.6 \pm 1.1 \mathrm{mmol} / \mathrm{L}$ $(118 \pm 21.2 \mathrm{mg} / \mathrm{dL})$ and $40.6 \pm 4.6 \mathrm{mmol} / \mathrm{mol}(5.9 \% \pm 0.4$ $\%)$, respectively. The average age was higher and renal function was lower in the IGT or T2DM group than the NGT group.

\section{Differing from UG, UMI was increased linearly along with an increase in plasma glucose, and no threshold for UMI was observed}

To examine the influence of plasma glucose levels on the excretion of UMI or UG, we collected urine samples at 2 hours after a $75 \mathrm{gOGTT}$ from a series of 46 subjects at Ehime University Hospital and measured the UMI

Table 1 Characteristics of participants in the study 2

\begin{tabular}{|c|c|c|c|c|}
\hline & NGT & IGT & T2DM & $P$ value \\
\hline Age, years & $47.4 \pm 12.0$ & $65.4 \pm 9.4$ & $63.9 \pm 9.9$ & $<0.0001$ \\
\hline Gender, n (male/female) & $63(15 / 48)$ & $29(9 / 20)$ & $23(12 / 11)$ & 0.0427 \\
\hline $\mathrm{BMI}, \mathrm{kg} / \mathrm{m}^{2}$ & $23.4 \pm 4.0$ & $24.2 \pm 3.5$ & $24.5 \pm 3.0$ & 0.3837 \\
\hline FPG, mmol/L (mg/dL) & $5.0 \pm 0.4(90 \pm 6.7)$ & $5.6 \pm 0.7(101 \pm 11.9)^{\star \star \star}$ & $6.6 \pm 1.1(118 \pm 21.2)^{\star \star \star}$ & $<0.0001$ \\
\hline 2-hour PG, mmol/L (mg/dL) & $5.5 \pm 1.0(99 \pm 18.0)$ & $8.9 \pm 1.0(161 \pm 17.6)^{\star \star \star}$ & $12.9 \pm 2.9(233 \pm 51.4)^{\star * \star}$ & $<0.0001$ \\
\hline FIRI, pmol/L ( $\mu \mathrm{IU} / \mathrm{mL})$ & $37.5 \pm 17.4(5.4 \pm 2.5)$ & $46.5 \pm 32.0(6.7 \pm 4.6)$ & $46.5 \pm 29.1(6.7 \pm 4.2)$ & 0.1412 \\
\hline $\mathrm{HbA} 1 \mathrm{c}, \mathrm{mmol} / \mathrm{mol}(\%)$ & $31.2 \pm 3.7(5.0 \pm 0.3)$ & $36.0 \pm 3.9(5.4 \pm 0.4)^{\star \star \star}$ & $40.6 \pm 4.6(5.9 \pm 0.4)^{\star \star \star}$ & $<0.0001$ \\
\hline Total cholesterol, mmol/L (mg/dL) & $5.3 \pm 1.1(203 \pm 40.9)$ & $5.2 \pm 0.9(200 \pm 34.8)$ & $5.3 \pm 1.4(203 \pm 53.3)$ & 0.92 \\
\hline HDL cholesterol, mmol/L (mg/dL) & $1.7 \pm 0.5(66 \pm 21.0)$ & $1.4 \pm 0.4(54 \pm 14.8)^{\star}$ & $1.4 \pm 0.4(52 \pm 14.8)^{\star \star}$ & 0.0018 \\
\hline eGFR, $\mathrm{ml} / \mathrm{min} / 1.73 \mathrm{~m}^{2}$ & $83.0 \pm 20.1$ & $74.0 \pm 16.9^{*}$ & $68.7 \pm 15.6^{\star \star}$ & 0.0005 \\
\hline
\end{tabular}

The values were presented as mean $\pm S D$ or $n$.

${ }^{*} \mathrm{P}<0.05$; versus NGT, ${ }^{\star *} \mathrm{p}<0.01$; versus NGT, and ${ }^{* * *} \mathrm{p}<0.001$; versus NGT.

BMI, body mass index; eGFR, estimated glomerular filtration rate; FIRI, fasting immunoreactive insulin; FPG, fasting plasma glucose;

HDL, high-density lipoprotein; IGT, impaired glucose tolerance; NGT, normal glucose tolerance; PG, plasma glucose; T2DM, type 2

diabetes mellitus. 

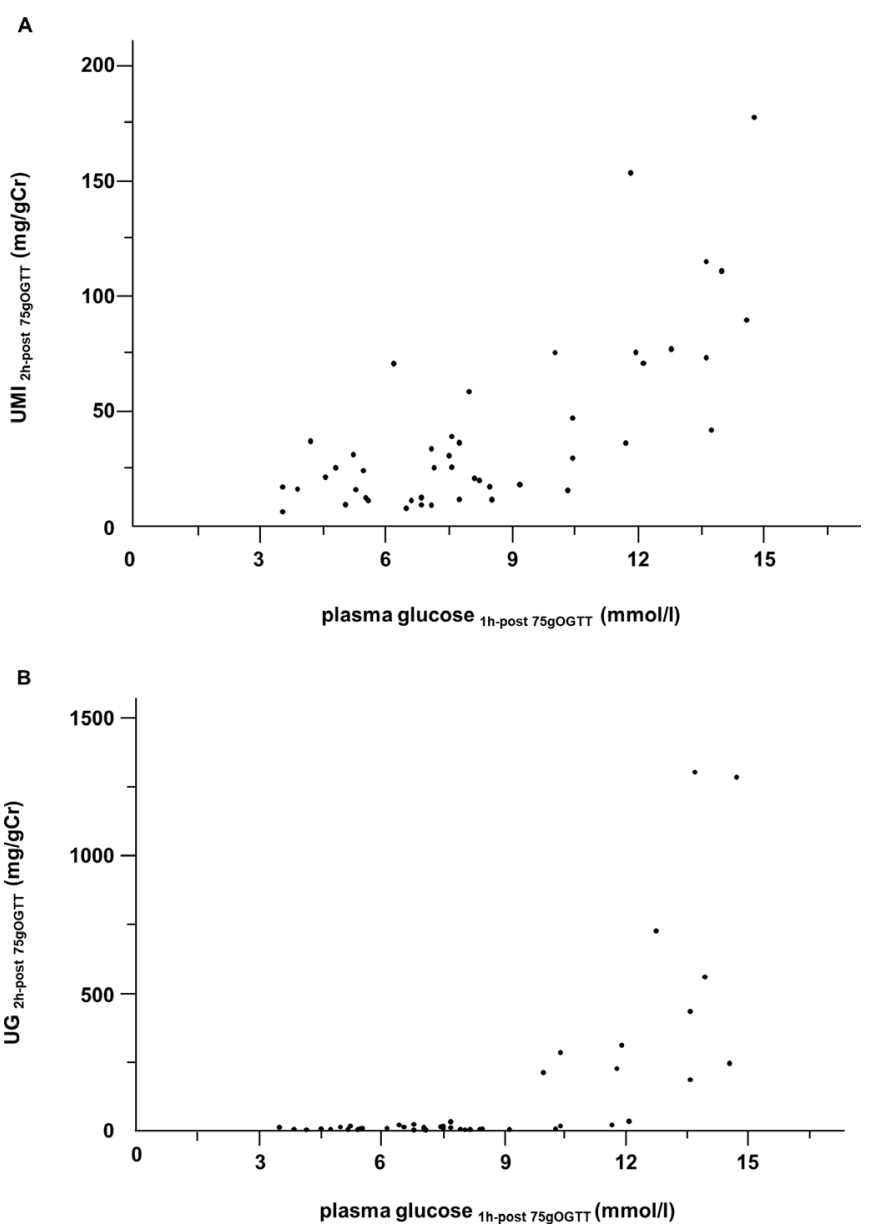

Figure 1 The relation between plasma glucose concentration at 1-hour post-75gOGTT and UMI (A) or UG (B) excretion at 2-hour post-75gOGTT (n=46). UMI $\mathrm{UM}_{\text {2h-post- }}$ 75gOGT, UMI/Cr at 2-hour post-75gOGTT; $U_{\text {2h-post-75gOGTT, }}$ UG/ Cr at 2-hour post-75gOGTT; and plasma glucose ${ }_{1 \text { h-post-75gOGT, }}$ plasma glucose level at 1-hour post-75gOGTT. $75 \mathrm{gOGTT}$, $75 \mathrm{~g}$ oral glucose tolerance test; UG, urinary glucose; UMI, urinary myoinositol.

and UG levels (figure 1). It is well known that UG has a renal threshold for glucose. Consistent with previous reports, ${ }^{2930} \mathrm{UG}$ at 2-hour post-75gOGTT ( $\mathrm{UG}_{2 \mathrm{~h} \text {-post-75gOGTT }}$ ) was detected via an increase in plasma glucose at 1-hour post-75gOGTT (plasma glucose ${ }_{1 \text { h-post-75gOGTT }}$ ), and the threshold concentration for detection was approximately $8.9-10.5 \mathrm{mmol} / \mathrm{L}$ (160-190 mg/dL). In contrast, no such threshold for UMI at 2-hour post-75gOGTT $\left(\mathrm{UMI}_{2 \mathrm{~h}-}\right.$ post-75gOGTT) was observed. $\mathrm{UMI}_{2 \mathrm{~h}-\text { post-75gOGTT }}$ was increased linearly along with an increase in plasma glucose ${ }_{1 \mathrm{~h} \text {-post- }}$ 75gOGTT $\left(R^{2}=0.67, \mathrm{p}<0.001\right)$.

\section{Relation between glucose parameters from blood samples} collected at hospital and MI levels from urine samples collected at home

We next assessed the relation between glucose and HbAlc levels from blood samples collected at hospital and UMI levels in urine samples collected at home $(n=115$, table 2$)$. Multivariate regression analyses revealed that after adjustment for age, sex, BMI and serum creatinine, UMI for all of the three time frames, including wake-up time $\left(\mathrm{UMI}_{\text {wake-up }}\right)$, premeal (UMI $\left.\mathrm{Uremeal}\right)$, 2-hour postprandial $\left(\mathrm{UMI}_{2 \mathrm{~h} \text {-postprandial }}\right)$, and $\Delta \mathrm{UMI}$ were associated with glucose parameters obtained from a 75gOGTT and HbA1c at hospital. $\mathrm{UMI}_{2 \mathrm{~h}-\text { postprandial }}$ at home was most closely associated with $\mathrm{HbAl} \mathrm{c}$ and plasma glucose level fasting and at 2 hours after a $75 \mathrm{gOGTT}$ at ADA criteria for diabetes.

\section{UMI levels before and after ingestion of test meal at home were} higher in subjects with diabetes

Repeated measures ANOVA (figure 2A) and MannWhitney test (figure 2B-E) showed significant differences between diabetes and non-diabetes in UMI before and after ingestion of test meal at home. UMI ${ }_{\text {wake-up }}$ UMI ${ }_{\text {premeal }}$, $\mathrm{UMI}_{\text {2h-postprandial, }}$ and $\Delta \mathrm{UMI}$ were higher in subjects with diabetes than non-diabetes, even after adjusted for age, sex, BMI and serum creatinine $(43.5 \pm 5.2$ vs $23.2 \pm 2.5$, $\mathrm{p}<0.01,36.2 \pm 4.6$ vs $20.3 \pm 2.3, \mathrm{p}<0.01,67.8 \pm 5.8$ vs $24.3 \pm 2.9$, $\mathrm{p}<0.001$, and $33.7 \pm 4.2$ vs $4.3 \pm 2.1, \mathrm{p}<0.001$, respectively).

Furthermore, $\mathrm{UMI}_{\text {wake-up }}, \mathrm{UMI}_{2 \mathrm{~h}-\text { postprandial }}$ and $\Delta \mathrm{UMI}$ were higher in subjects with GI than NGT, even after adjusted for age, sex, BMI and serum creatinine (36.1 \pm 4.2 vs $20.7 \pm 3.6, \quad \mathrm{p}<0.01,47.7 \pm 5.0$ vs $21.8 \pm 4.4, \quad \mathrm{p}<0.01$, and $19.3 \pm 3.6$ vs $3.4 \pm 3.2, \mathrm{p}<0.05$, respectively).

\section{ROC curve analyses to determine the optimum cut-off values of UMI associated with diabetes}

To further assess the usefulness of UMI levels in urine samples collected at home for the screening of diabetes, we performed ROC curve analyses (table 3). For the screening of diabetes, the area under the curve (AUC) for ROC (AUCROC) for $\mathrm{UMI}_{2 \mathrm{~h} \text {-postprandial }}$ was 0.83 , with a sensitivity of $76 \%$ and a specificity of $81 \%$ at a cut-off value of $32 \mathrm{mg} / \mathrm{gCr}(\mathrm{p}<0.0001)$. The AUCROC for $\triangle \mathrm{UMI}$ was 0.82 with a sensitivity of $80 \%$ and a specificity of $80 \%$ at a cut-off value of $7.4 \mathrm{mg} / \mathrm{gCr}(\mathrm{p}<0.0001)$. The AUCROC for $\mathrm{UMI}_{2 \mathrm{~h} \text {-postprandial }}$ and $\triangle \mathrm{UMI}$ were not statistically inferior to that for $\mathrm{HbAlc} \geq 48 \mathrm{mmol} / \mathrm{mol}(6.5 \%)$ using the ADA criteria for diabetes. Furthermore, for the screening of GI, the AUCROC for $\mathrm{UMI}_{2 \mathrm{~h} \text {-postprandial }}$ was 0.74 and $\triangle \mathrm{UMI}$ was $0.69(\mathrm{p}<0.0001$, online supplementary table 2$)$.

These results suggest that measuring MI in urine samples collected at home before and after the ingestion of the commercially available test meal would be a simple and non-invasive screening method for diabetes.

\section{DISCUSSION}

In the present study, we found that: (1) MI level in urine samples collected at home was associated with blood glucose parameters obtained from a $75 \mathrm{gOGTT}$ and HbA1c at hospital; (2) $\mathrm{UMI}_{2 \mathrm{~h}-\text { postprandial }}$ was closely associated with plasma glucose level at before and 2 hours after a 75gOGTT at criteria for testing for diabetes in ADA; (3) UMI was higher in diabetic subjects than nondiabetic subjects and in subjects with GI than NGT even after adjusted for age, sex, BMI and serum creatinine. We obtained similar results when we included five subjects 
Table 2 Relation between glucose parameters from blood samples collected at hospital and UMI levels from self-collected urine samples at home

\begin{tabular}{|c|c|c|c|c|}
\hline Dependent variables & Independent variables & $\begin{array}{l}\text { Non-standardized } \beta \\
(95 \% \mathrm{Cl})\end{array}$ & Standardized $\beta$ & $P$ value \\
\hline \multirow{4}{*}{$\begin{array}{l}75 \mathrm{gOGTT} \\
\text { Fasting plasma glucose }\end{array}$} & In UMI wake-up $_{\text {}}$ & 18.5 (9.5 to 27.4$)$ & 0.36 & $<0.0001^{*}$ \\
\hline & In UMI & 16.3 (7.2 to 25.4$)$ & 0.30 & $0.0006^{\star}$ \\
\hline & 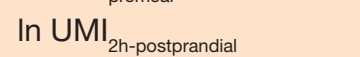 & 21.9 (14.0 to 29.8$)$ & 0.44 & $<0.0001^{*}$ \\
\hline & In $\Delta \mathrm{UMI}$ & 4.9 (1.2 to 8.6$)$ & 0.24 & $0.0097^{\star}$ \\
\hline \multirow{4}{*}{$\begin{array}{l}75 \mathrm{gOGTT} \\
1 \text {-hour plasma glucose }\end{array}$} & In UMI wake-up & 54.0 (24.9 to 83.1) & 0.29 & $0.0004^{*}$ \\
\hline & In UMI & 48.5 (18.1 to 78.8$)$ & 0.25 & $0.0020^{*}$ \\
\hline & In UMI ${ }_{2 h \text {-postprandial }}$ & 73.8 (47.9 to 99.7$)$ & 0.41 & $<0.0001^{\star}$ \\
\hline & In $\Delta \mathrm{UMI}$ & 12.5 (0.9 to 24.0 ) & 0.18 & 0.0347 \\
\hline \multirow{4}{*}{$\begin{array}{l}\text { 75gOGTT } \\
\text { 2-hour plasma glucose }\end{array}$} & In UMI $\left.\right|_{\text {wake-up }}$ & 37.4 (3.7 to 71.0$)$ & 0.19 & 0.0298 \\
\hline & In UMI & 33.3 (0.2 to 66.3$)$ & 0.17 & 0.0488 \\
\hline & In UMI ${ }_{2 h \text {-postprandial }}$ & 72.5 (44.5 to 100.6$)$ & 0.40 & $<0.0001^{\star}$ \\
\hline & In $\Delta \mathrm{UMI}$ & 17.8 (5.3 to 30.2$)$ & 0.25 & $0.0058^{*}$ \\
\hline \multirow{4}{*}{$\begin{array}{l}75 \mathrm{gOGTT} \\
\text { AUC }_{0-2 h} \text { glucose }\end{array}$} & In UMI wake-up & 81.9 (37.2 to 126.7$)$ & 0.29 & $0.0005^{\star}$ \\
\hline & In UMI & 73.3 (27.4 to 119.2 ) & 0.24 & $0.0020^{*}$ \\
\hline & In UMI ${ }_{2 h \text {-postprandial }}$ & $121.0(82.9$ to 159.1$)$ & 0.44 & $<0.0001^{\star}$ \\
\hline & In $\Delta \mathrm{UMI}$ & 23.8 (6.1 to 41.5$)$ & 0.22 & $0.0089^{\star}$ \\
\hline \multirow[t]{4}{*}{$\mathrm{HbA1c}$} & In UMI wake-up & 0.33 (0.06 to 0.59$)$ & 0.20 & 0.0152 \\
\hline & In UMI ${ }_{\text {premeal }}$ & 0.32 (0.06 to 0.59$)$ & 0.19 & 0.0165 \\
\hline & In UMI ${ }_{2 h \text {-postprandial }}$ & 0.55 (0.33 to 0.78 ) & 0.36 & $<0.0001^{\star}$ \\
\hline & In $\Delta \mathrm{UMI}$ & 0.13 (0.03 to 0.23$)$ & 0.21 & 0.0133 \\
\hline
\end{tabular}

Multivariable regression analyses adjusted for age, sex, BMI, and serum creatinine. Dependent variables: fasting plasma glucose, 1-hour post-75gOGTT plasma glucose, 2-hour post-75gOGTT plasma glucose, AUC ${ }_{0-2 h}$ glucose of $75 \mathrm{gOGTT}$, and HbA1c. Independent variables: the logarithm of $\mathrm{UMI}_{\text {wake-up }}$, UMI at wake-up time (fasting first urine); $\mathrm{UMI}_{\text {premeal }}$, UMI at premeal (fasting second urine); and $\mathrm{UMI}{ }_{2 \mathrm{~h}-\mathrm{postprandial}}, \mathrm{UMI}$ at 2-hour postprandial. $\triangle \mathrm{UMI}$ was defined by 2-hour postprandial UMI minus premeal UMI.

* $P$ values remained significant after Bonferroni's correction.

AUC, area under the curve; BMI, body mass index; 75gOGTT, $75 \mathrm{~g}$ oral glucose tolerance test; UMI, urinary myoinositol.

with isolated IFG in GI; and (4) no adverse events were observed in our UMI test.

We also found that, different from UG, no threshold for UMI was detected. UMI increased linearly with increasing plasma glucose (figure 1). MI is transported from extracellular fluid via three inositol transporters: sodium-dependent MI transporters 1 and 2, and $\mathrm{H}^{+}$myoinositol transporter, which cotransports myoinositol with $\mathrm{H}^{+} .{ }^{1431}$ These transporters are competed by D-glucose when hyperglycemia is present before UG is detected. ${ }^{14}$ Actually, UMI levels were increased in subjects with diabetes even when their UG was not detected by a urine dipstick test (no.1, 108 mg/gCr and no.10, $97 \mathrm{mg} / \mathrm{gCr}$ in online supplementary table 1 ). Therefore, the properties of UMI permit it to screen early stage of T2DM. Indeed, in the present study, subjects had no current or history of diabetes, the majority of them were diagnosed by 2-hour plasma glucose level after a 75gOGTT, and HbA1c in the T2DM group was $40.6 \pm 4.6 \mathrm{mmol} / \mathrm{mol}(5.9 \% \pm 0.4 \%)$.

Shelf life testing demonstrated that different from UG, UMI was stable at RT and under more severe conditions as $37^{\circ} \mathrm{C}$ without preservative. However, compared with
UMI, UCr was unstable at $37^{\circ} \mathrm{C}$. The estimated shelf life of $\mathrm{UCr}$ was 7 days at RT and 2 days at $37^{\circ} \mathrm{C}$. Therefore, correction for $\mathrm{UCr}$ is not acceptable under conditions of high temperature over 2 days. Concerning mailing a sample under severe conditions of high temperature, we further analyzed the usefulness of UCr-uncorrected UMI on the screening of diabetes. Even though the AUCROC of $\mathrm{UMI}_{2 \mathrm{p}-\text { pstprandial }}$ and $\triangle \mathrm{UMI}$ were slightly decreased ( 0.83 to 0.80 and 0.82 to 0.77 , respectively), using UCruncorrected UMI may be reasonable under the condition of high temperature over $37^{\circ} \mathrm{C}$ (online supplementary table 3 ).

These results suggest that the UMI test would be suitable for subjects with limited access to medical care because of financial problems and locality and would be the first step towards further medical examinations. For example, subjects could mail urine samples collected at home before and after the ingestion of prescribed test meal like commercially available energy bar to a laboratory for analysis at ambient temperature, and when UMI was high, they could be advised to visit a medical institution for further advanced examinations of diabetes. 

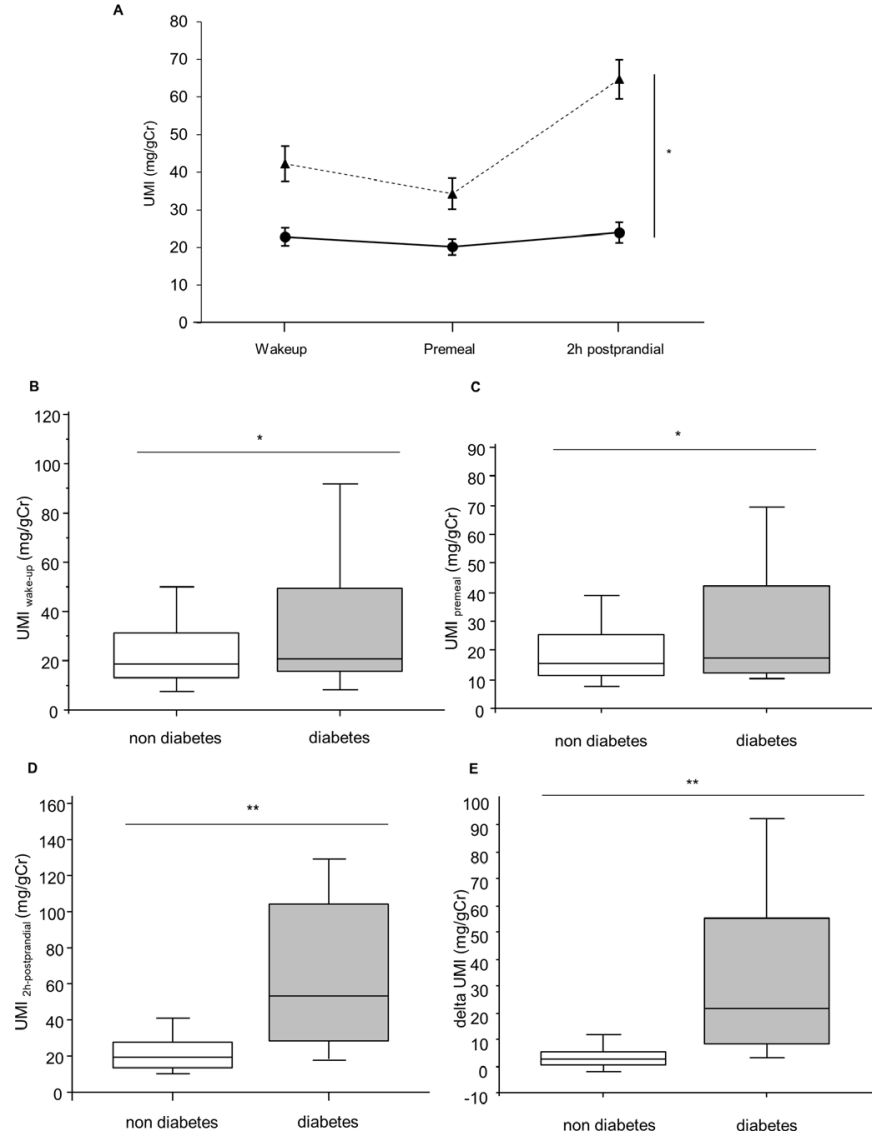

Figure 2 Comparison of UMI between subjects with or without diabetes during ingestion of test meal. (A) Solid line: subjects without diabetes $(n=92)$; dotted line: subjects with diabetes $(n=23)$. Error bars represent $S E{ }^{*} p<0.001$ computed by repeated-measures ANOVA. (B-E) Box plots indicating the 5th and 95th percentiles (vertical lines), 25th and 75th (boxes), and 50th percentiles (horizontal lines). ${ }^{*} \mathrm{P}<0.05$ and ${ }^{* *} \mathrm{p}<0.0001$ computed by Mann-Whitney test. UMI UMI at wake-up time; UMI ${ }_{\text {premeal, }}$ UMI at premeal; UMI ${ }_{2 h-}$ postprandial, UMI at 2-hour postprandial; $\triangle \mathrm{UMI}, \mathrm{UMI}_{2 \mathrm{~h} \text {-postprandial }}$ minus UMI premeal ANOVA, analysis of variance; UMI, urinary myoinositol.

A 75gOGTT at a hospital is widely used as the gold standard for the screening and diagnosis of GI. However, (1) a 75 gOGTT usually requires multiple (2-5 times) blood collections, (2) there is a risk of hyperglycemia and problems associated with blood collection, (3) it is a relatively costly test, ${ }^{32}$ and (4) the test can be a burden for the staff if many subjects are scheduled at one time. However, the UMI test is (1) available at home, (2) non-invasive, (3) inexpensive (compared with a 75gOGTT at hospital, at one-tenth the price in Japan), and (4) the UMI test has a few limitations in terms of the number of samples. These results suggest that the UMI test, as discussed here, would be more suitable for mass screening for diabetes or GI than a $75 \mathrm{gOGTT}$.

Previous studies have reported that UMI was increased in cases of renal failure. ${ }^{33}$ Therefore, to reduce the impact of renal function on UMI, (1) we excluded subjects with chronic renal dysfunction (eGFR of $<30 \mathrm{ml}$ / $\left.\min / 1.73 \mathrm{~m}^{2}\right)$, (2) UMI were corrected by UCr, and (3) we performed multivariate regression analyses adjusted for serum creatinine.

There are some limitations in this study. First, the period from the last meal to wake-up time when subjects first collected fasting urine was dependent on the individual. Therefore, the influence of the supper on $\mathrm{UMI}_{\text {wake-up }}$ may be different. Second, in the present study, we excluded subjects with eGFR $<30 \mathrm{ml} / \mathrm{min} / 1.73 \mathrm{~m}^{2}$. Therefore, to further clarify the influence of renal function on UMI for screening for diabetes, study of larger general population including subjects with several renal dysfunction will be necessary. Third, the urine samples were shipped to a single laboratory at ambient temperature at our region $\left(5^{\circ} \mathrm{C}-26^{\circ} \mathrm{C}\right)$, and the $\mathrm{UMI}$ and $\mathrm{UCr}$ levels were then measured within 2 days of the urine collection. Therefore, further investigation of samples under various conditions, periods and temperature of storage will be necessary.

In conclusion, measuring MI levels in urine samples collected at home before and after the ingestion of the test meal would be a simple, non-invasive, and valuable screening method for diabetes in subjects without chronic renal dysfunction. UMI test at home would be more suitable for mass screening for diabetes as the first step toward further investigation such as a $75 \mathrm{gOGTT}$ for a more definitive diagnosis at hospital.

Table 3 Receiver operating characteristics (ROC) curve for potential predictors of diabetes

\begin{tabular}{|c|c|c|c|c|c|c|c|}
\hline Parameter & AUCROC $(95 \% \mathrm{Cl})$ & Cut-off & $\begin{array}{l}\text { P value of AUCROC } \\
\text { compared with HbA1c }\end{array}$ & Sensitivity & Specificity & PPV & NPV \\
\hline $\mathrm{HbA} 1 \mathrm{c}, \mathrm{mmol} / \mathrm{mol}(\%)$ & 0.90 (0.83 to 0.98$)$ & $48(6.5)^{\star}$ & - & 0.08 & 1.00 & 1.00 & 0.80 \\
\hline $\mathrm{UMI}_{\text {wake-up }}, \mathrm{mg} / \mathrm{gCr}$ & 0.64 (0.49 to 0.78$)$ & 18 & $<0.001$ & 0.73 & 0.49 & 0.27 & 0.87 \\
\hline $\mathrm{UMI}_{\text {premeal }}, \mathrm{mg} / \mathrm{gCr}$ & $0.62(0.48$ to 0.76$)$ & 14 & $<0.0001$ & 0.64 & 0.40 & 0.23 & 0.80 \\
\hline $\mathrm{UMI}_{2 \mathrm{~h} \text {-postprandial }}, \mathrm{mg} / \mathrm{gCr}$ & 0.83 (0.73 to 0.93$)$ & 32 & 0.13 & 0.76 & 0.81 & 0.53 & 0.92 \\
\hline$\Delta \mathrm{UMI}, \mathrm{mg} / \mathrm{gCr}$ & $0.82(0.71$ to 0.93$)$ & 7.4 & 0.18 & 0.80 & 0.80 & 0.53 & 0.94 \\
\hline
\end{tabular}

$\triangle \mathrm{UMI}$ was defined as 2-hour postprandial UMI minus premeal UMI.

*American Diabetes Association criteria for diabetes as $\mathrm{HbA} 1 \mathrm{c} \geq 48 \mathrm{mmol} / \mathrm{mol}(6.5 \%)$ was used as reference standard.

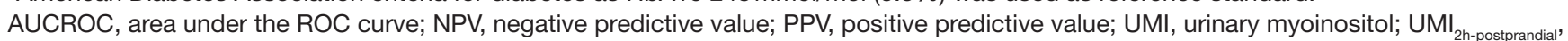

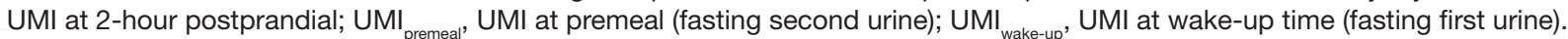


Author affiliations

'Department of Diabetes and Molecular Genetics, Ehime University Graduate School of Medicine, Toon, Ehime, Japan

${ }^{2}$ Genki Plaza Medical Center for Health Care, Chiyoda, Tokyo, Japan

${ }^{3}$ Ehime Prefectural Central Hospital, Matsuyama, Ehime, Japan

${ }^{4}$ Saijyo Central Hospital, Saijyo, Ehime, Japan

${ }^{5}$ National Hospital Organization, Toon, Ehime, Japan

${ }^{6}$ Institute for Adult Diseases, Asahi Life Foundation, Chuo-ku, Japan

Acknowledgements We wish to thank Akiko Otaki and Risa Kagawa at Ehime University for technical assistance.

Contributors All authors confirm that they meet the International Committee of Medical Journal Editors uniform requirements for authorship. Specifically, MT, YT, FY, SK and HO designed the experiments. MT, YT, FY, MY, GH, SS, JF and SK collected the data. MT, YT, FY and SK analyzed data. MT, YT and HO wrote the manuscript. YT is the guarantors of this work. All of the authors give full consent for publication of the present manuscript. All authors are responsible for the integrity of the work as a whole.

Funding This study was supported by Japan Diabetes Foundation, OMRON Corporation, ASAHI KASEI Pharma Corporation, and Sysmex Corporation.

Disclaimer The funders were not involved in the design of the study, the collection, analysis, and interpretation of data, writing the report, or the decision to submit the report for publication.

Competing interests None declared.

Patient consent for publication Not required.

Ethics approval Study protocols were approved by the research ethics committee of each hospitals.

Provenance and peer review Not commissioned; externally peer reviewed.

Data availability statement All data relevant to the study are included in the article or uploaded as supplementary information.

Open access This is an open access article distributed in accordance with the Creative Commons Attribution Non Commercial (CC BY-NC 4.0) license, which permits others to distribute, remix, adapt, build upon this work non-commercially, and license their derivative works on different terms, provided the original work is properly cited, appropriate credit is given, any changes made indicated, and the use is non-commercial. See: http://creativecommons.org/licenses/by-nc/4.0/.

ORCID iD

Yasunori Takata http://orcid.org/0000-0002-6530-4078

\section{REFERENCES}

1 Ogurtsova K, da Rocha Fernandes JD, Huang Y, et al. IDF diabetes atlas: global estimates for the prevalence of diabetes for 2015 and 2040. Diabetes Res Clin Pract 2017;128:40-50.

2 NCD Risk Factor Collaboration (NCD-RisC). Worldwide trends in diabetes since 1980: a pooled analysis of 751 population-based studies with 4.4 million participants. Lancet 2016;387:1513-30.

3 National Center for Chronic Disease Prevention and Health Promotion. National diabetes statitics report, 2017. Available: www. cdc.gov [Accessed 16 Sep 2019].

4 Tuomilehto J, Lindström J, Eriksson JG, et al. Prevention of type 2 diabetes mellitus by changes in lifestyle among subjects with impaired glucose tolerance. N Engl J Med 2001;344:1343-50.

5 Knowler WC, Barrett-Connor E, Fowler SE, et al. Reduction in the incidence of type 2 diabetes with lifestyle intervention or metformin. N Engl J Med 2002;346:393-403.

6 DECODE Study Group, the European Diabetes Epidemiology Group. Glucose tolerance and cardiovascular mortality: comparison of fasting and 2-hour diagnostic criteria. Arch Intern Med 2001;161:397-405.

7 Takao T, Suka M, Yanagisawa H, et al. Impact of postprandial hyperglycemia at clinic visits on the incidence of cardiovascular events and all-cause mortality in patients with type 2 diabetes. $J$ Diabetes Investig 2017;8:600-8.

8 Selph S, Dana T, Blazina I, et al. Screening for type 2 diabetes mellitus: a systematic review for the U.S. preventive services Task force. Ann Intern Med 2015;162:765-76.
9 Barry E, Roberts S, Oke J, et al. Efficacy and effectiveness of screen and treat policies in prevention of type 2 diabetes: systematic review and meta-analysis of screening tests and interventions. BMJ 2017;356:i6538.

10 Alam U, Asghar O, Azmi S, et al. General aspects of diabetes mellitus. Handb Clin Neurol 2014;126:211-22.

11 Takahashi $Y$, Inoue $Y$, Hirata $Y$. The prevalence of neuropathic symptoms in diabetic patients newly referred to our Hospital. Tohoku $J$ Exp Med 1983;141 Suppl:439-45.

12 Polonsky WH. Poor medication adherence in diabetes: what's the problem? J Diabetes 2015;7:777-8.

13 González L, Elgart JF, Gagliardino JJ. [Education of people with type 2 diabetes through peers with diabetes: is it cost effective?]. Medwave 2015;15:e6348.

14 Croze ML, Soulage CO. Potential role and therapeutic interests of myo-inositol in metabolic diseases. Biochimie 2013;95:1811-27.

15 Thomas MP, Mills SJ, Potter BVL. The "other" inositols and their phosphates: Synthesis, biology, and medicine (with recent advances in myo-inositol chemistry). Angew Chem Int Ed Engl 2016;55:1614-50.

16 Kennington AS, Hill CR, Craig J, et al. Low urinary chiro-inositol excretion in non-insulin-dependent diabetes mellitus. $N$ Engl $\mathrm{J}$ Med 1990;323:373-8.

17 Ostlund RE, McGill JB, Herskowitz I, et al. D-Chiro-Inositol metabolism in diabetes mellitus. Proc Natl Acad Sci U S A 1993:90:9988-92.

18 Yoshii $\mathrm{H}$, Uchino $\mathrm{H}$, Ohmura $\mathrm{C}$, et al. Clinical usefulness of measuring urinary polyol excretion by gas-chromatography/massspectrometry in type 2 diabetes to assess polyol pathway activity. Diabetes Res Clin Pract 2001;51:115-23.

19 Ikezaki H, Furusyo N, Okada K, et al. The utility of urinary myoinositol as a marker of glucose intolerance. Diabetes Res Clin Pract 2014;103:88-96.

20 Sarashina G, Yamakoshi M, Noritake M, et al. A study of urinary myo-inositol as a sensitive marker of glucose intolerance. Clin Chim Acta 2004;344:181-8.

21 Yamakoshi M, Kawazu S. Lucica MI urinary myoinositol kit: a new diagnostic test for diabetes mellitus and glucose intolerance. Mol Diagn Ther 2008;12:189-91.

22 American Diabetes Association. 2. Classification and diagnosis of diabetes: standards of medical care in diabetes-2019. Diabetes Care 2019;42:S13-28.

23 Morioka N, Funada J-ichi, Takata Y, et al. Influence of meal intake on pulse wave indices in type 2 diabetes. Hypertens Res 2010;33:743-7.

24 Funada J-ichi, Takata Y, Hashida H, et al. Dysfunctional central hemodynamic regulation after daily meal intake in metabolic syndrome. Atherosclerosis 2010;210:268-73.

25 Capen R, Christopher D, Forenzo P, et al. Evaluating current practices in shelf life estimation. AAPS PharmSciTech 2018;19:668-80

26 Bajaj S, Singla D, Skhuja N. Stability testing of pharmaceutical products. J App Pharm Sci 2012;2:129-38.

27 European medicines agancy. International cooperation on harmonisation of technical requirements for registration of veterinary medicinal products $(\mathrm{VICH})$. Statistical evaluation of stability data 2013. Available: www.ema.europa.eu/en/documents/scientificguideline/international-cooperation-harmonisation-technicalrequirements-registration-veterinary-medicinal_en-0.pdf [Accessed 16 Sep 2019]

28 Bossuyt PM, Reitsma JB, Bruns DE et al. Stard 2015: an updated list of essential items for reporting diagnostic accuracy studies. Clin Chem 2015;61:1446-52.

29 Lawrence RD. Renal threshold for glucose: normal and in diabetics. BMJ 1940;1:766-8.

30 Wright EM, Loo DDF, Hirayama BA. Biology of human sodium glucose transporters. Physiol Rev 2011;91:733-94.

$31 \mathrm{Fu} \mathrm{H}$, Li B, Hertz L, et al. Contributions in astrocytes of SMIT1/2 and $\mathrm{HMIT}$ to myo-inositol uptake at different concentrations and $\mathrm{pH}$. Neurochem Int 2012;61:187-94.

32 Zhang P, Engelgau MM, Valdez R, et al. Costs of screening for pre-diabetes among US adults: a comparison of different screening strategies. Diabetes Care 2003;26:2536-42.

33 Niwa T, Yamamoto N, Maeda K, et al. Gas chromatographic--mass spectrometric analysis of polyols in urine and serum of uremic patients. Identification of new deoxyalditols and inositol isomers. $J$ Chromatogr 1983;277:25-39.

34 Pitkänen E. Changes in serum and urinary myo-inositol levels in chronic glomerulonephritis. Clin Chim Acta 1976;71:461-8. 